\title{
Suicidal Ideation During a Year After the Earthquake: A Letter to Editor
}

\author{
Kosar Yousefi ${ }^{1}$, Zakieh Rezaie ${ }^{2}$ and Ali Sahebi (id ${ }^{3, *}$ \\ ${ }^{1}$ Ilam University of Medical Sciences, Ilam, Iran \\ ${ }^{2}$ Msc in Social Work, Ilam, Iran \\ ${ }^{3}$ Department of Health in Disasters and Emergencies, School of Public Health and Safety, Shahid Beheshti University of Medical Sciences, Tehran, Iran \\ "Corresponding author: Department of Health in Disasters and Emergencies, School of Public Health and Safety, Shahid Beheshti University of Medical Sciences, Tehran, Iran. \\ Tel: +98-9183434703, Emails: ali.sahebi@sbmu.ac.ir; nurse.sahebi@yahoo.com
}

Received 2018 November 22; Revised 2019 April 26; Accepted 2019 May 25.

\section{Dear Editor,}

Several psychological consequences, such as suicidal ideation, can be created the aftermath of natural disasters. Various predisposing factors, such as major depression, mental health problems, severe property destruction, life threats, and economic conditions, can be related to the increased suicide rate after disasters (1). This is a report of a systematic review and meta-analysis. The searches of the study were performed in electronic databases including PubMed, Scopus, Web of Science, Google Scholar, MagIran, and SID using the following English keywords or their equivalent in Persian: suicide, earthquake, natural disasters, prevalence, during one year, ideation, thought, as well as their combinations using (AND) and (OR) operators. The searches were conducted in the period of 2014 to 2018. The study was conducted based on the PRISMA (preferred reporting items for systematic reviews and meta-analyses) guidelines. The researchers assessed the quality of studies using the STROBE checklist (2). After applying the inclusion and exclusion criteria and qualitative assessment, two studies with good quality finally entered the meta-analysis $(3,4)$. These studies reported suicidal ideation 6,11 , and 12 months after the earthquake. The total sample size included 1352 women and men. Since the prevalence rate has a binomial distribution, the variance of the prevalence was calculated using the binomial distribution formula and the average weight was used to combine the prevalence rate in different studies. In order to evaluate the heterogeneity of the selected studies, the $\mathrm{I}^{2}$ index was used. The heterogeneity of the studies was estimated to be moderate $\left(\mathrm{I}^{2}=73.30 \% \mathrm{P}=0.024\right)(5)$. The prevalence of suicide ideation during a year after the earthquake was $33 \%$ with $95 \%$ CI of $27-38 \%$ and P-value of 0.024 . Among the risk factors affecting suicidal ideation after the earthquake was depression as the most influential factor (4). The prevalence of suicidal ideation during a year after the earthquake had a significantly decreasing trend according to the year of study.
The suicide rate is 5.3 per 100,000 population in Iran ranging from 3.6 for females to 7.0 for males (6). In Daliri et al. study, the prevalence of suicide in Iran was 8 per 100,000 population and despite the decreasing trend, the rate of suicide was reported high in the western provinces of Iran (7). Iran experienced a devastating earthquake in Kermanshah in $2017(8,9)$. The survivors of the earthquake following the loss of livelihood, property, parents, and other family members can be exposed to psychological and social problems, which can lead to despair and suicidal ideation. The occurrence of an earthquake, its consequences, and suicide susceptibility can be the risk factors for psychological problems such as suicidal ideation in the affected areas. Therefore, it is suggested that special protective actions be taken by the relevant organizations to prevent psychosocial problems in the survivors of earthquakes. Therefore, by identifying and timely screening of at-risk survivors and protecting them, suicide ideation can be largely prevented.

\section{Footnotes}

Authors' Contribution: Study design: Kosar Yousefi. Data collection: Zakieh Rezaie. Analysis and writing manuscript: Ali Sahebi.

Declaration of Interest: The authors declared that they have no conflicts of interest.

Funding/Support: This study did not receive any financial support.

\section{References}

1. Stratta P, Capanna C, Carmassi C, Patriarca S, Di Emidio G, Riccardi I, et al. The adolescent emotional coping after an earthquake: a risk factor for suicidal ideation. J Adolesc. 2014;37(5):605-11. doi: 10.1016/j.adolescence.2014.03.015. [PubMed: 24931563].

2. Azami M, Tardeh Z, Mansouri A, Soleymani A, Sayehmiri K. Mean blood lead level in Iranian workers: A systematic and meta-analysis. Iran Red Crescent Med J. 2018;20(1). e64172. doi: 10.5812/ircmj.64172. 
3. Wang XL, Yip PS, Chan CL. Suicide prevention for local public and volunteer relief workers in disaster-affected areas. J Public Health Manag Pract. 2016;22(3):E39-46. doi: 10.1097/PHH.0b013e31829a303c. [PubMed: 23760310].

4. Ran MS, Zhang Z, Fan M, Li RH, Li YH, Ou GJ, et al. Risk factors of suicidal ideation among adolescents after Wenchuan earthquake in China. Asian J Psychiatr. 2015;13:66-71. doi: 10.1016/j.ajp.2014.06.016. [PubMed: 25845324].

5. Sayehmiri K, Tavan $\mathrm{H}$. [Systematic review and meta-analysis methods prevalence of peptic ulcer in Iran]. Govaresh. 2015;20(4):250-8. Persian.

6. Karimi J, Holakouie-Naieni K, Koehler SA, Soleymanpour A, Karimi R, Mohammad K. A forensic epidemiological investigation of the char- acteristics of completed suicides in Isfahan province, Iran.J Psychiatry Behav Sci. 2018;12(2). doi: 10.5812/ijpbs.8035.

7. Daliri S, Bazyar J, Sayehmiri K, Delpisheh A, Sayehmiri F. [Investigation of the Incidence rate of suicide in Iran During Years 2001-2014: A Systematic Review and Meta-analysis study]. J Shahid Sadoughi Univ Med Sci. 2016;24(9):7574-68. Persian.

8. Safarpour H. Donors management in disasters: Kermanshah earthquake experience. Iran Red Crescent Med J. 2018;20(11). e84942. doi 10.5812/ircmj.84942.

9. Yousefi K, Pirani D, Sahebi A. Lessons learned from the 2017 Kermanshah earthquake response. Iran Red Crescent Med J. 2018;20(12). doi: 10.5812/ircmj.87109. 